\title{
Vascular Endothelial Growth Factor Expression in Correlation with Stage Juvenile Nasopharyngeal Angiofibroma
}

\author{
Ifiq Budiyan Nazar, Yussy Afriani Dewi, Agung Dinasti Permana \\ Department of Otorhinolaryngology-Head and Neck Surgery Faculty of Medicine Universitas \\ Padjadjaran/Dr. Hasan Sadikin General Hospital, Bandung, Indonesia
}

\section{Abstract}

Background: Juvenile Nasopharyngeal Angiofibroma (JNA) is a benign tumor of mesenchymal tissue, originating from the stromal and blood vessels with dense collagen. However, JNA has a malignant tumor-like property because it can cause erosion of surrounding bone. Vascular Endothelial Growth Factor (VEGF) plays a role in the angiogenesis process. The expression of VEGF is the best marker to determine the occurrence of angiogenesis in JNA. This study aimed to determine the correlation between VEGF expression and JNA clinical stage.

Methods: This was a cross-sectional correlational analytic observational study on medical records and paraffin blocks of all patients with JNA at Dr. Hasan Sadikin General Hospital Bandung during the period of 2016 to 2019. Immunohistochemistry examination of VEGF expressions was performed and VEGF expression was rated based on staining intensity, percentage distribution, and histoscore. Data were then analyzed using the Spearman correlation test.

Results: Of 24 patients, 23 males and 1 female, 58\% demonstrated a strong intensity of staining. The positivity of VEGF cell percentage was identified as $26-50 \%(n=6$ patients), $51-75 \%(n=11)$, and $>75 \%(\mathrm{n}=7)$. The median VEGF histoscores were $2.5,6.5$, and 12 in JNA stage I, stage II, and stage 3, respectively, with the greater VEGF histoscore had a higher clinical stage with a correlation coefficient of (rs) 0.723 (p=0.002).

Conclusions: There is a strong correlation between increased VEGF expression and JNA clinical stage. VEGF expression can be used as a prognostic factor of JNA.

Keywords: Angiogenesis, juvenile nasopharyngeal angiofibroma, staging, vascular endothelial growth factor

\section{Introduction}

Juvenile Nasopharyngeal Angiofibroma (JNA) is a mesenchymal tumor with its constituent tissue originating from the stromal and blood vessels with dense collagen. The tumor predominantly arises from the superior part of the sphenopalatine foramen and the posterolateral wall of the nasopharynx. ${ }^{1}$ Juvenile Nasopharyngeal Angiofibroma is a histologically benign, but clinically malignant tumor because it can damage the bone and extend to the surrounding tissue. . $^{2,3}$

The incidence of JNA is $0.05-0.5 \%$ of all head and neck tumors and is relatively occurred more in India and Egypt compared to America and Europe. Moreover, in Asia, the incidence is around 1: 5,000 while in the Middle East 1 : 60,000 . These lesions are almost always found in adolescent male patients, in the age range of 9-19 years with the highest incidence between the ages of 14-18 years. ${ }^{4-6}$ In Indonesia, JNA is reported 2 to 4 cases in 1 year. $^{7}$ At Dr. Hasan Sadikin General Hospital Bandung, there were 112 JNA patients for the period of 2011-2018 with 111 male and 1 female, and most of them were in the age range of 10-20 years. ${ }^{8}$

The staging of the tumor can be seen from the CT scan results with the classification system based on the expansion of the tumor; the higher the clinical stage, and the more extensive lesions caused. The most commonly used and developed system in recent literature is the Radkowski classification.

Correspondence: Ifiq Budiyan Nazar, Department of Otorhinolaryngology-Head and Neck Surgery Faculty of Medicine Universitas Padjadjaran/Dr. Hasan Sadikin General Hospital, Jalan Pasteur No 38, Bandung, Indonesia, E-mail: ifiq82nazar@gmail.com 
This assessment includes the extension to the posterior pterygoid and the rate of skull base erosion. This system considers the choice of surgical approach and the risk of recurrence. ${ }^{4,5}$

The cause of JNA is not yet clearly known, being genetic factors, molecular alterations, HPV infections, and related to hormones that may play an important role in JNA development. ${ }^{9}$ The Growth of tumor tissue is related to increased estrogen production and reduced production of androgen hormones..$^{10}$ Furthermore, JNA has biological characteristics of angiogenic histogenetic tumors. ${ }^{11}$ Various attempts to determine tumor pathogenesis have been carried out by studying the expression of growth factors and oncogenes such as C-KIT and C-MYC. Those studies support that vascular endothelial cells can become postembryonic undifferentiated mesenchyme cells and can be induced into other mesenchymal non-hemopoietic cell phenotypes. The GSTM1 gene has been involved in the formation of JNA. Loss of GSTM1 expression or null genotype has been observed in these tumors.

Angiogenesis in tumors is influenced by angiogenic factors such as basic Fibroblast Growth Factor (bFGF), Vascular Endothelial Growth Factor (VEGF), angiogenin, Transforming Growth Factor (TGF), thrombopoietin, angiopoietin I, cytokines, angiogenic enzymes, and indirect activated activation factor. The VEGF encourages enzymes and proteins that are important for the process of degradation of the basic membrane, useful for endothelial cells for migration and invasion which are important stages in angiogenesis. Overexpression of VEGF is associated with tumor progression and prognosis in various tumors, including JNA. Furthermore, the VEGF contributes to proliferation and suggests the promotion of vascularity. The increased neovascularization, decreased apoptosis, and increased endothelial cell proliferation may lead to progressive and increased clinical stages. ${ }^{12,13}$

Study on immunohistochemical examination for the VEGF, TGF $\beta$, estrogen and progesterone receptors (ER-PR), and proliferating cell nuclear antigen (PCNA), taken from anatomic pathological preparations of JNA patients has shown that VEGF, TGF $\beta$, and PCNA are widely expressed in JNA tissue, and are positively related to the clinical stage and the prognosis of JNA. ${ }^{14}$

The expression and subcellular distribution of several angiogenesis factors have been studied such as TGF $\beta$, bFGF, VEGF-R 1-2, and
Hypoxia Inducible Factor (HIF-1 $\alpha) \cdot{ }^{15}$ The results show that the growth of vascularization and the progression of the clinical stage of JNA are influenced by factors released by fibroblasts in the stroma. However, the effect of VEGF is still debatable. Interestingly, VEGF expression is not significantly related to the puberty status, stage of the tumor, intraoperative blood loss, and the recurrence of the JNA. $^{16}$

The VEGF has a central role in the pathways and stages of tumor angiogenesis, and especially the degradation of extracellular matrix and proliferation of vascular endothelial cells. Increased endothelial cell proliferation will further increase microvascular density as well as increase VEGF expression. The VEGF expression is the best marker for determining the precence of angiogenesis in JNA. ${ }^{15}$ Therefore, the aim of this study was to determine the correlation between VEGF expression and the clinical stage of JNA.

\section{Methods}

This study was a correlational analytic with a cross-sectional design. The secondary data of medical records of all JNA patients at Dr. Hasan Sadikin General Hospital Bandung period 2016-2019 was used, including the data of immunohistochemistry examination taken from paraffin blocks The study was conducted from May to October 2019. This study protocol was approved by the Ethics Committee of Hasan Sadikin Hospital no: LB.02.01/ X.6.5 / $185 / 2019$.

Inclusion criteria were data of patients diagnosed with JNA, whereas the exclusion criteria were patients with residual or recurrent JNA and incomplete medical records. The patients were then divided into three stages, using Radkowski. Tumor size was determined based on tumor diameter $\leq 4$ $\mathrm{cm}$ and $>4 \mathrm{~cm}$.

The immunohistochemistry (IHC) examination of the paraffin block conducted in the Anatomical Pathology section of the Dr. Hasan Sadikin General Hospital was further classified according to the clinical stage. The VEGF expression was examined as followed: immunohistochemical smear with antibodies against VEGF was performed with the incubation with VEGF primary antibodies (mouse monoclonal antibody anti-human VEGF, $100 \mu \mathrm{g}$, PA1080, BosterBio-USA) with a 1:200 dilution for one night; the incubation with secondary antibodies for 30 minutes; the enzymatic detection system ABC (Avidin- 
Biotin Complex) using peroxidase, and $\mathrm{DAB}$ (Diamino Benzidin) enzymes as counterstain enzymes using Hematoxylin Eosin. The positive values were indicated by golden brown to the old color.

The expression of VEGF was assessed on the stromal and endothelial cells of the tumor and was counted visually with a multiheaded binocular light microscope at 400x magnification performed by 2 examiners at the same time and preparation. The VEGF expression was further rated based on staining intensity, percentage distribution, and VEGF histoscore. The score for the intensity of cell absorption on IHC staining was divided into a score of 0 or negative/ when there was no VEGF expression, a score of $1+$ or weak, a score of $2+$ or moderate, $3+$ or strong. Of all tumor cells expressing positive, the distribution percentage score was determined for $<25 \%$ $(1+), 26-50 \%(2+), 51-75 \%(3+)$, and $>75 \%$ $(4+)$

The VEGF expression was calculated semiquantitatively using the $\mathrm{H}$-score formula with the formula [intensity $\mathrm{x}$ distribution]. The $\mathrm{H}$ score were 0 or negative, $1-4$ as weakly positive, $5-8$ as moderate positive, and $9-12$ as strongly positive.

\section{Results}

In total, 24 data was retrieved diagnosed with JNA according to the inclusion and exclusion
Table 1 Clinical Characteristic of Patients with Juvenile Nasopharyngeal Angiofibroma at Dr. Hasan Sadikin General Hospital Bandung Period 2016-2019

\begin{tabular}{|c|c|}
\hline Variable & Total \\
\hline $\begin{array}{l}\text { Gender } \\
\text { Male } \\
\text { Female }\end{array}$ & $\begin{array}{c}23 \\
1\end{array}$ \\
\hline $\begin{array}{c}\text { Age (year) } \\
10-14 \\
15-19 \\
20-24\end{array}$ & $\begin{array}{l}14 \\
8 \\
2\end{array}$ \\
\hline Mean (SD) & $15.6(3.4)$ \\
\hline Range & $11-24$ \\
\hline
\end{tabular}

Note: $\mathrm{SD}=$ standard deviation

criteria, being the youngest age found was 11 years and the oldest age was 24 years. The mean age was 15.6 years old (standard deviation, SD 3.4 years), as shown in Table 1.

The relationship between VEGF expression and tumor size according to the clinical stage as depicted in Table 2 . The intensity ratio based on clinical stage showed a correlation coefficient (rs) of 0.414 ( $\mathrm{p}=0.044$, Spearman correlation test), indicating a significant relationship between the intensity of staining of VEGF expression to clinical stage. Furthermore, the percentage of VEGF distribution showed a significant correlation

Table 2 Relationship between Stage of Juvenile Nasopharyngeal Angiofibroma with VEGF Expression, Histoscore, and Tumor Size

\begin{tabular}{|c|c|c|c|c|c|c|}
\hline \multirow{3}{*}{ VEGF expression } & \multicolumn{3}{|c|}{ JNA Stage } & \multirow{2}{*}{ Total } & \multirow{3}{*}{$\begin{array}{l}\text { Correlation } \\
\text { Coefficient } \\
\text { (rs) }\end{array}$} & \multirow{3}{*}{ p-value* } \\
\hline & I & II & III & & & \\
\hline & $\mathrm{n}$ & $\mathrm{n}$ & $\mathrm{N}$ & $\mathrm{n}$ & & \\
\hline $\begin{array}{l}\text { Intensity of Staining } \\
\text { Weak } \\
\text { Strong }\end{array}$ & $\begin{array}{l}5 \\
3\end{array}$ & $\begin{array}{l}4 \\
4\end{array}$ & $\begin{array}{l}1 \\
7\end{array}$ & $\begin{array}{l}10 \\
14\end{array}$ & 0.414 & 0.044 \\
\hline $\begin{array}{l}\text { Distribution Percentage } \\
<25 \% \\
26-50 \% \\
51-75 \% \\
>75 \%\end{array}$ & $\begin{array}{l}- \\
6 \\
2\end{array}$ & $\begin{array}{l}- \\
- \\
7 \\
1\end{array}$ & $\begin{array}{l}- \\
- \\
2 \\
6\end{array}$ & $\begin{array}{c}- \\
6 \\
11 \\
7\end{array}$ & 0.832 & $<0.001$ \\
\hline $\begin{array}{l}\text { VEGF Histoscore ** } \\
\text { Median } \\
\text { Range }\end{array}$ & $\begin{array}{l}2.5 \\
2-9\end{array}$ & $\begin{array}{c}6.5 \\
3-9\end{array}$ & $\begin{array}{c}12 \\
4-12\end{array}$ & & 0.723 & 0.002 \\
\hline $\begin{array}{l}\text { Tumor Size } \\
\quad \leq 4 \mathrm{~cm} \\
>4 \mathrm{~cm}\end{array}$ & $\begin{array}{l}4 \\
4\end{array}$ & $\overline{8}$ & $\overline{8}$ & $\begin{array}{c}4 \\
20\end{array}$ & 0.548 & 0.006 \\
\hline
\end{tabular}

Note: VEGF= Vascular Endothelial Growth Factor; JNA, Juvenile Nasopharyngeal Angiofibroma; rs= Correlation Coefficient, ${ }^{*}$ Spearman test $p<0.05 ;{ }^{* *}$ Histoscore in median 


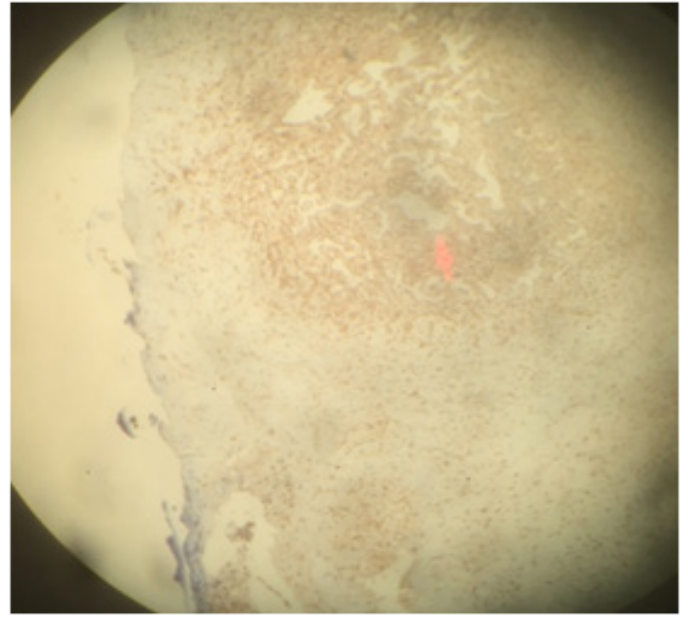

A

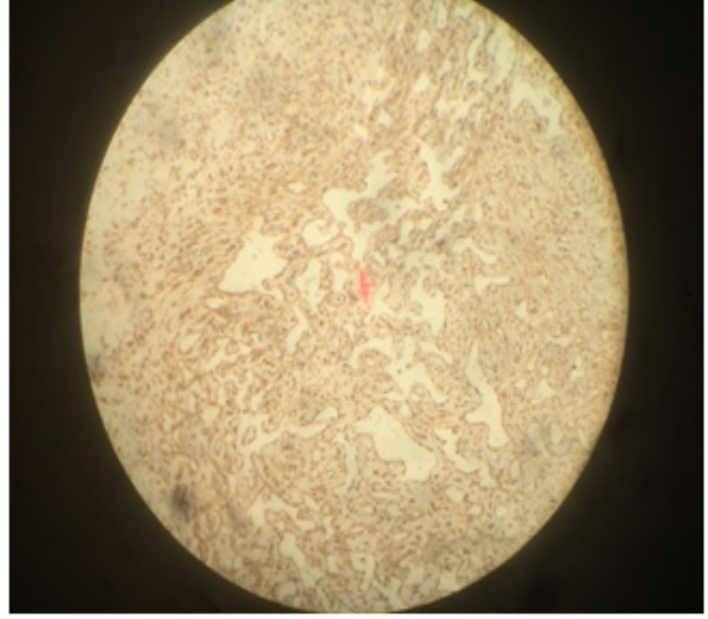

B

Figure 1 Intensity of Staining of VEGF Expression

Note: A= Weak Expression (IHC 200x) B= Strong Expression (IHC 200x)

with Spearman correlation of $0.832(\mathrm{p}<0.001)$ with the clinical stage.

The VEGF histoscore variable median for stage I, stage II, and stage III were 2.5, 6.5, and 12 , respectively. The rs the VEGF histoscore to the clinical stage was $0.723(p=0.002)$, suggesting that there was a significant relationship between VEGF histoscore and VEGF expression variable at ANB clinical stage. The greater the VEGF histoscore value, the higher the clinical stage (Table 2).

This study observed the intensity of the immunoreactivity and the percentage of positive cells that were initially estimated semi-quantitatively by light microscopy at 200x magnification in stromal cells and endothelial cells of JNA (Figure 1). Weak expression of VEGF was shown by pale brown color and positive cell distribution $<25 \%$ (Figure 1A), while strong expression showed

Table 3 Relationship between Tumor Size with Age and VEGF Expression

\begin{tabular}{|c|c|c|c|c|c|}
\hline & \multicolumn{2}{|c|}{ Tumor Size } & \multirow{2}{*}{ Total } & \multirow{2}{*}{$\begin{array}{c}\text { Correlation } \\
\text { Coefficient } \\
\text { (rs) }\end{array}$} & \multirow[b]{2}{*}{ p-value* } \\
\hline & $\leq 4 \mathrm{~cm}$ & $>4 \mathrm{~cm}$ & & & \\
\hline $\begin{array}{l}\text { Age (year) } \\
10-14 \\
15-19 \\
20-24\end{array}$ & $\begin{array}{l}4 \\
- \\
-\end{array}$ & $\begin{array}{c}10 \\
8 \\
2\end{array}$ & $\begin{array}{l}14 \\
8 \\
2\end{array}$ & 0.479 & 0.018 \\
\hline $\begin{array}{l}\text { VEGF Expression } \\
\text { Intensity of Staining } \\
\text { Weak } \\
\text { Strong }\end{array}$ & $\begin{array}{l}4 \\
-\end{array}$ & $\begin{array}{c}6 \\
14\end{array}$ & $\begin{array}{l}10 \\
14\end{array}$ & 0.529 & 0.008 \\
\hline $\begin{array}{l}\text { Distribution Percentage } \\
<25 \% \\
26-50 \% \\
51-75 \% \\
>75 \%\end{array}$ & $\begin{array}{l}4 \\
- \\
-\end{array}$ & $\begin{array}{c}2 \\
11 \\
7\end{array}$ & $\begin{array}{c}- \\
6 \\
11 \\
7\end{array}$ & 0.625 & 0.001 \\
\hline $\begin{array}{l}\text { VEGF Histoscore *) } \\
\text { Median }\end{array}$ & 2 & 9.5 & - & 0.660 & $<0.001$ \\
\hline
\end{tabular}

Note: VEGF=Vascular Endothelial Growth Factor; rs= Correlation Coefficient, *Spearman test $\mathrm{p}<0.05$; ** Histoscore in median 
dark brown staining and cell distribution $>75 \%$ (Figure 1B). Based on radiological examination using CT Scan, it showed that there was a relationship between tumor size and JNA stage with the correlation coefficient value of $0.6(p=0.002$, Spearman test).

The relationship between tumor size and age in JNA patients showed a significant correlation coefficient of $0.479 \quad(\mathrm{p}=0.018)$, as well the correlation between tumor size and VEGF staining intensity that showed a statistical of rs $0.529 \quad(p=0.008)$. The correlation to percentage distribution was $0.625(\mathrm{p}=0.001)$, and to the VEGF histoscore was $0.660(\mathrm{p}<0.001)$ (Table 3$)$.

\section{Discussion}

Our study has explored the correlation between VEGF expression and the clinical stage of Juvenile Nasopharyngeal Angiofibroma (JNA) at Dr. Hasan Sadikin General Hospital Bandung period 2016-2019. The JNA patients are predominantly male in this study, with the most prevalent age group is between 10-15 years old (54\%), conforming to various studies in Malaysia ${ }^{17}$ as well in Jakarta, Indonesia. ${ }^{2}$ JNA has a predilection in the adolescent boys age range of 7-21 years with the highest incidence between the ages of 14-18 years and rarely at the age of 25 years. ${ }^{6}$ Although the etiology of nasopharyngeal angiofibroma is unknown, this might be related to hormonal imbalance, ${ }^{4,9}$ such as an excess estrogen production or androgen deficiency. ${ }^{4,18}$ It seems that there is a relationship between tumors with the sex and age of the patient. ${ }^{7}$

In this study, strong staining (58.3\%) and distribution percentage of $>50 \%(75 \%)$ are the most predominant result of the VEGF examination. The VEGF expression has a significant correlation with the clinical stage (Table 2). Many studies had reported the escalation of VEGF expression in JNA, suggesting that the escalation of VEGF expression in JNA is correlated with the advanced clinical stage. ${ }^{10,15}$ However, another study has reported a different finding, VEGF expression had no significant correlation with clinical stage of JNA. ${ }^{16}$

As a pro-angiogenic growth factor that has a prominent role in tumor biology, VEGF could induce vasculogenesis and angiogenesis. VEGF has a correlation with the increase of proliferation and the density of blood vessels. ${ }^{10}$ However, some others show that proangiogenic factor in benign tumors has more effects towards blood vessel growth compared to tumor growth. ${ }^{19}$

The determination of the JNA stage is based on the results of a CT scan with contrast. The characteristic assessment of CT scans is tumor size. There is a relationship between tumor size and JNA clinical stage. High expression of VEGF also has influenced the increase in tumor size. The higher the level of VEGF expression, the larger the tumor size. Previous studies have shown similar results, angiogenesis affects tumor growth. ${ }^{1,18}$ In tumor growth, neovascularization has two effects; namely supplying nutrients and oxygen, and the newly formed endothelial cells that stimulate the growth of tumor cells around them, through the secretion of polypeptides such as PDGF, GM-CSF, and IL-1. In cancers with high cell proliferation, tumor growth is faster, showing that the larger tumor size the higher degree of histopathology. ${ }^{20}$

The limitation of the study is difficulty in getting JNA patients with stage I. Furthermore, the process of staining the IHC with antibodies to VEGF requires a long incubation time and dilution several times to get good results on sample readings.

In conclusion, there is a strong correlation between increased VEGF expression and the JNA stage. Higher of VEGF expression may worsen the prognosis of JNA. Examination of VEGF expression can be used as a marker to assess the prognostic factors of JNA.

\section{References}

1. Shancez-Romero C, Carlos R, Molina JPD, Thompson LDR, de Almeida OP, Pina AR. Nasopharyngeal angiofibroma: a clinical, histopathological and immunohistochemical study of 42 cases with emphasis on stromal features. Head Neck Pathol. 2018;12(1):52-61

2. Anggreani L, Adham M, Musa Z, Lisnawati, Bardosono S. Gambaran ekspresi reseptor estrogen $\beta$ pada angiofibroma nasofaring belia dengan menggunakan pemeriksaan imunohistokimia. ORLI. 2011;41(1):8-16

3. SunX, Guo L, Wang H, Yu H, WangJ, MengX, et al. The presence of tumor-infiltrating IL-17 producing cells in juvenile nasopharyngeal angiofibroma tumor microenvironment is a poor prognostic factor. Am J Otolaryngol. 2014;35(5):582-8

4. Nicolai P, Schreiber A, Villaret AB. Juvenile angiofibroma: evolution of management. Int J Pediatr. 2012;2012:412545.

5. Garcea MF, Yuca SA, Yuca K. Juvenile Nasopharyngeal Angiofibroma. Eur J Gen 
Med. 2010;7(4):419-25.

6. Persky M., Manolidis. S. Vascular tumors of the head and neck. In: Johnson JT, Rosen CA. Editors. Bailey's head and neck surgery-otolaryngology 5th (ed). Baltimore: Lippincott Williams \& Wilkins: 2014. p.1999-2031.

7. Adham M, Zahara NP, Suroyo I, Lisnawati, Bardosono S. Relationship of radiological and surgical variables and vascular endothelial growth factor expression with recurrence in juvenile nasopharyngeal angiofibroma. Journal of Physic: Conference Series. 2018;1073(4):042038.

8. Dewi YA, Nazar IB. Management of juvenile nasopharyngeal angiofibroma in a refferal hospital in West Java, Indonesia. Althea Medical Journal. 2020;7(1):45-50.

9. Li W, Ni Y, Lu H, Hu L, Wang D. Current perspectives on the origin theory of juvenile nasopharyngeal angiofibroma. Discov Med. 2019;27(150):245-54.

10. Liu Z, Wang J, Wang $\mathrm{H}$, Wang $\mathrm{D}, \mathrm{Hu} \mathrm{L}$, Liu $\mathrm{Q}$ et al. Hormonal receptors and vascular endothelial growth factor in juvenile nasopharyngeal angiofibroma: immunohistochemical and tissue microarray analysis. Acta Otolaryngol. 2015; 135(1):51-7.

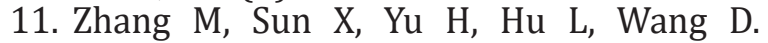
Biological distinctions between juvenile naopharyngeal angiofibroma and vascular malformation: immunohistochemical study. Acta Histochem. 2011;113(6):626-30.

12. Melincovici CS, Boşca AB, Şuşman S, Márginean $\mathrm{M}$, Mihu $\mathrm{C}$, Istrate $\mathrm{M}$, et al. Vascular endothelial growth factor (VEGF)key factor in normal and pathological angiogenesis. Rom J Morphol Embryol. 2018;59(2):455-67.

13. Le T, New J, Jones JW, Usman S, Yalamanchali
S, Tawfik 0 , et al. Inhibition of fibroblast growth factor receptor with AZD4547 mitigates juvenile nasopharyngeal angiofibroma. Int Forum Allergy Rhinol. 2017;7(10):973-79.

14. Saylam G, Yücel OT, Sungur A, Onerci M. Proliferation, angiogenesis and hormonal markers in juvenile nasopharyngeal angiofibroma. Int J Pediatr Otorhinolaryngol. 2006;70(2):227-34.

15. Schuon R, Brieger J, Heinrich YR, Szyfter W, Mann WJ. Immunohistochemical analysis of growth mechanisms in juvenile nasopharyngeal angiofibroma. Eur Arch Otorhinolaryngol. 2007;264(4):389-94.

16. Hota A, Sarkar C, Gupta SD, Kumar R, Bhalla AS, Thakar A. Expression of vascular endothelial growth factor in juvenile angiofibroma. Int J Pediatr Otorhinolaryngol. 2015;79(6):900-2.

17. Saniasiaya J, Abdullah B, Ramli RR. Surgical management and outcome of juvenile nasopharyngeal angiofibroma in a single centre: a fifteen year experience. Egypt J Ear Nose Throat Allied Sci. 2016:18(1): 39-41.

18. Ralli M, Fusconi M, Visconti IC, Martelucci S, de Vincentis M, Greco A. Nasopharyngeal angiofibroma in an elderly female patient: a rare case report. Mol Clin Oncol. 2018; 9(6):702-4.

19. Pandey P, Mishra A, Tripathi AM, Verma V, Trivedi R, Singh HP, et al. Current molecular profile of juvenile nasopharyngeal angiofibroma: first comprehensive study from India. Laryngoscope. 2016;127(3): E100-106.

20. Hong IS. Stimulatory versus suppressive effects of GM-CSF on tumor progression in multiple cancer types. Exp Mol Med. 2016;48(7):e242. 